Massimo Rogante*, Irina K. Domanskaya, Ekaterina S. Gerasimova, Adél Len, László Rosta, Noémi K. Székely and Elena Vladimirova

\title{
Nanoscale investigation of polymer cement concretes by small angle neutron scattering
}

\begin{abstract}
An analysis of dense cements, such as polymer cement concrete, is made to produce original innovative components for different types of constructing materials. These materials present good functional properties (ageing resistance, crack formation resistance, hardness, and stability of mechanical modules) and can be used for various applications. In this paper, experimental tests on Portland cement with added $\gamma-\mathrm{Al}_{2} \mathrm{O}_{3}$ and redispersible dry polymer performed using small angle neutron scattering are reported. The objective of the investigation was to assess the key parameters of the material (e.g., porosity, fractal dimensions, and size distribution) at the nanoscale level as well as to obtain useful structural information for expanding the possibility of applications. The results obtained can contribute to the optimisation of the consistency of the material, the design of operating conditions of elements of structures and facilities, and the design of the procedures that support ecological criteria and enhance quality and safety levels.
\end{abstract}

Keywords: cement stones; industrial applications; polymer cement concretes; porosity; SANS.

DOI 10.1515/secm-2015-0013

Received January 13, 2015; accepted April 18, 2015; previously published online June 3, 2015

\section{Introduction}

The investigations of cements are generally carried out for gathering information about the aspects related to

\footnotetext{
*Corresponding author: Massimo Rogante, Rogante Engineering Office, Contrada San Michele 61, 62012 Civitanova Marche, Italy, e-mail:main@roganteengineering.it.

http://orcid.org/0000-0002-6846-0826

Irina K. Domanskaya, Ekaterina S. Gerasimova and Elena Vladimirova: Institute of Material Sciences and Metallurgy, Ural Federal University, 19, Mira Str., 620002 Yekaterinburg, Russian Federation Adél Len, László Rosta and Noémi K. Székely: Wigner Research Centre for Physics, Institute for Solid State Physics and Optics, Pf.49, 1525 Budapest, Hungary
}

microstructure and nanostructure, fatigue behaviour, and computational mechanics. These investigations rely on tests, theoretical studies, and simulation-based analyses. The study of parameters, such as hydration degree of binder, balance between crystalline and gel phases of formed hydrated compounds, and morphology and sizes of crystal hydrates, is also essential. Different methods, such as X-ray diffraction, differential thermal analysis, infrared spectroscopy, optical microscopy, and electronic microscopy, are used for this purpose. The behaviour of the cement after its ageing can be predicted by stress analysis and model-based simulations, and building construction safety can be improved. Porosity can be considered as the main factor affecting mechanical and heat-insulating properties. Porosity measurements are done by gravimetric methods, gas and liquid porosimetry (e.g., mercury intrusion porosimetry), and acoustic methods. The acoustic-electric method establishes the relation between porosity and the characteristics of electric and acoustic responses to their pulsed mechanical excitation [1].

The study of cements and related materials is also important for creating novel advanced composite materials with elevated functional properties such as durability (e.g., the cement's aptitude to resist the infiltration of liquids and oxygen), resistance to ageing, crack formation, and stability of mechanical modules. Neutron beam techniques are being progressively considered as effective nondestructive methods for exploring and modifying the internal nanofeatures of materials throughout an extensive range of disciplines in engineering, chemistry, physics, and medicine. These tools represent a key answer also in the case of the cement to extend the lifetime of the materials and prevent ageing-related degradation. Neutrons can reveal significant properties (such as structural or magnetic properties), allowing the assessment of responses to external influences over the specimen's entire volume $[2,3]$. What differentiates the neutron techniques from other investigation tools is its capability to capture information about the material's microstructure and nanostructure in the whole sample volume, down to 
$\sim 10 \AA(1 \mathrm{~nm})$, as well as to study the material in the neutron beam without any previous sample preparation, which in some cases inevitably changes the material's structure [2].

In this work, polymer cement concrete (PCC) specimens, produced by the Department of Building Materials of the Ural Federal University (DBM-URFU), made of Portland cement with added $\gamma-\mathrm{Al}_{2} \mathrm{O}_{3}$ and redispersible dry polymer (RDP) with different additive ratios have been investigated by small angle neutron scattering (SANS), with the aim to recognise the influence of these additives on their nanostructure. This work is a part of a full study of novel cements and related materials that the Rogante Engineering Office has designed by adopting advanced methodologies, including, for example, laser interferometry (the latter with the aim to identify the vibration characteristic parameters and analyse the resonance modes for each investigated material) [4].

Previous SANS analyses on cements were especially aimed to characterise porosity. SANS investigations were performed, for example, on hydrated Portland cement paste specimens of various water-to-cement ratios of $0.4,0.8$, and 1.4, confirming the existence of two different fractal structures in the nanometric regions of the cement calcium-silicate-hydrate (C-S-H) gel $[5,6]$. The SANS technique allowed characterising the pore structure and verify the pore size distribution in hardened cement pastes, studying the fine-pore porosity without any drying or pre-treatment of specimens. Measurements indicated a bimodal distribution of near-spherical pores with diameters of 5 and $12 \mathrm{~nm}$, and the pores appeared unaffected by the water-tocement ratios $[7,8]$. SANS was adopted together with $\mathrm{X}$-ray scattering technique to assess the composition and solid density of the main binding reaction product of cement hydration, C-S-H gel. The study allowed determining the mean formula and the mass density of the nanoscale $\mathrm{C}-\mathrm{S}-\mathrm{H}$ gel particles in hydrating cement as well as classifying water by its location, with implications for defining the chemically active (C-S-H) surface area within cement and for forecasting the concrete's properties [9].

In this paper, we report SANS measurements carried out to follow the influence of the different additives on the nanostructure of the investigated samples as well as to find the peculiarities of the structure of interfaces inside the cement stone. It has been assumed that these polymers change the concrete's structure when the binding agent and water form the cement stone, which joints particles together to make a monolith.

\section{Materials and methods}

\subsection{Polymer cement concretes}

PCCs and polymer cement mortar are cement-based composites with the addition of different high molecular weight compounds in the form of aqueous dispersions or in dry powdered form. The addition of the polymers permits varying the cement stone's structure towards the wished direction. It can lead to the creation of composite material with improved strength and elasticity, owing to the articulated joint of hydrates with more flexible particles, nets, and films of strong elastic organic polymers possessing adhesiveness. Thus, at that bending, the tensile strength, abrasive resistance, and chemical resistance are increased, whereas porosity and water absorption are reduced; the modulus of elasticity decreases with increasing polymer-to-cement ratio [10-15].

The active components of the PCC are the mineral binding agent and the organic matter. The binding agent and water form the cement stone, which joints the particles of aggregate together, to create a monolith. The polymer component and mineral binder have to be selected in an optimal way in order that the wished cement strength would be achieved. The polymer, during the removal of water from the concrete, forms a thin layer on the surface of pores, cement, and aggregate nodules, this layer having good adhesive performance; therefore, the added polymer retards the hardening process of cement stone.

The research carried out by the DBM-URFU has been devoted to finding the interaction type among cement, polymer, and $\mathrm{Al}_{2} \mathrm{O}_{3}$ ( $\gamma$-type) processes [10]. The chemical composition of the specimens investigated in this work included ordinary Portland cement, RDP-copolymer of vinyl acetate in powdered form (vinyl acetate and vinyl versatate having a temperature of vitrification of $5^{\circ} \mathrm{C}$, $100 \%$ content of solid substance, and a particle size of 80 $\mu \mathrm{m})$, and $\mathrm{Al}_{2} \mathrm{O}_{3}$.

$\gamma-\mathrm{Al}_{2} \mathrm{O}_{3}$ was produced at the Laboratory of the Institute of Solid State Chemistry of the Ural Branch of the Russian Academy of Sciences using the process of thermal hydrolysis [16]. The following reaction took place:

$$
\mathrm{AlCl}_{3} \cdot 6 \mathrm{H}_{2} \mathrm{O}+\mathrm{H}_{2} \mathrm{O} \rightarrow \gamma-\mathrm{Al}_{2} \mathrm{O}_{3}+\mathrm{HCl}+\mathrm{H}_{2} \mathrm{O}
$$

The initial material $\left(\mathrm{AlCl}_{3} \cdot 6 \mathrm{H}_{2} \mathrm{O}\right)$ was placed into the quartz tube of a Nabertherm furnace and heated until the temperature of thermal hydrolysis with water vapour was reached within $140 \mathrm{~min}$. In these conditions, the decomposition of $\mathrm{AlCl}_{3} \cdot 6 \mathrm{H}_{2} \mathrm{O}$ occurred and $\gamma-\mathrm{Al}_{2} \mathrm{O}_{3}$ was the final 
product of the reaction. Water vapour and $\mathrm{HCl}$ gases were captured with cold distilled water. Electroconductivity was measured within $140 \mathrm{~min}$, with an interval of $10 \mathrm{~min}$, using a HANNA HI 8733 multirange portable EC meter (HANNA instruments, Woonsocket, RI, USA). The electroconductivity growing values showed that the reaction finished, and all initial product was used. The target product was $\gamma-\mathrm{Al}_{2} \mathrm{O}_{3}$ powder with particle size of $<90 \mathrm{~nm}$. In the present work, two ways of polymer mixing have been studied: polymer dispersion by joint grinding and the dry blended method. Table 1 contains the list of the samples with the respective additives and the type of the mixing procedure.

Table 1: Composition and characteristics of the investigated PCC samples.

\begin{tabular}{llllr}
\hline Sample & $\begin{array}{l}\text { RDP } \\
\text { (wt.\%, type) }\end{array}$ & $\begin{array}{l}\boldsymbol{\gamma} \text {-Al } \mathbf{O}_{3} \\
(\mathbf{w t .})\end{array}$ & Mixing & $\begin{array}{r}\text { Sample thickness } \\
(\mathbf{m m})\end{array}$ \\
\hline S0 & - & - & Dry & 3.28 \\
S5 & - & Max & Dry & 3.65 \\
S6 & $2.5($ RDP-22) & - & Dry & 3.69 \\
S7 & $2.5($ RDP-23) & - & Dry & 3.66 \\
S8 & $2.5($ RDP-22) & Max & Dry & 3.45 \\
S9 & $2.5($ RDP-22) & Max & Wet & 3.64 \\
S10 & $2.5($ RDP-23) & Max & Dry & 3.72 \\
S11 & $2.5($ RDP-23) & Max & Wet & 2.88 \\
\hline
\end{tabular}

Max, maximum amount of nanostructured $\mathrm{Al}_{2} \mathrm{O}_{3}$. RDP-22 and RDP-23 are made by Rhodia, La Défense, France.
The S0 sample was the control sample; it did not contain any additives. This was modified via the addition of mineral substance $\left(\gamma-\mathrm{Al}_{2} \mathrm{O}_{3}\right.$ powder, S5) or polymers RDP-22 and RDP-23 (S6 and S7); finally, both additives $\left(\gamma-\mathrm{Al}_{2} \mathrm{O}_{3}+\mathrm{RDP}-22\right.$ or $\left.\gamma-\mathrm{Al}_{2} \mathrm{O}_{3}+\mathrm{RDP}-23\right)$ were used and introduced into S8 and S10 by dry mixing. Two of the threecomponent samples have been prepared by wet mixing (S9 and S11). The used mixing methods are as follows: for dry blending, powder of polymer and $\gamma-\mathrm{Al}_{2} \mathrm{O}_{3}$ added to the cement, being mixed for 2-3 min; for wet blending, joint grinding copolymer and $\gamma-\mathrm{Al}_{2} \mathrm{O}_{3}$ in tempering water using a planetary mill.

It is established that wet mixing increases the bending and compression strength by $10-15 \%$. It is possible to explain that, by this effect, there is a more homogeneous distribution of the polymer particles and $\mathrm{Al}_{2} \mathrm{O}_{3}$ in the cement composition.

Table 2 reports the characteristics of the RDP additives.

Figure 1 shows the scanning electron microscopy (SEM) pictures of cement stone with (S9) and without (S0) polymer addition. These micrographs have been made using a JEOL JSM-6390LA SEM instrument (JEOL, Peabody, MA, USA) at the Institute of Solid State Chemistry of the Ural Branch of the Russian Academy of Sciences.

The micrograph of the specimen without polymer addition shows the presence of gel phase and crystalline phases: hydroaluminate and hydrosilicate calcium. The maximal amount of gel phase belongs to specimens

Table 2: Characteristics of the RDP additives.

\begin{tabular}{lrlrr}
\hline RDP & Vitrification temperature $\left({ }^{\circ} \mathrm{C}\right)$ & Composition & Content of solid substance $(\%)$ & Particle size $(\mu \mathrm{m})$ \\
\hline 22 & 5 & Vinyl acetate+vinyl versatate & 100 & 80 \\
23 & 6 & Vinyl acetate+vinyl versatate & 100 & 90 \\
\hline
\end{tabular}

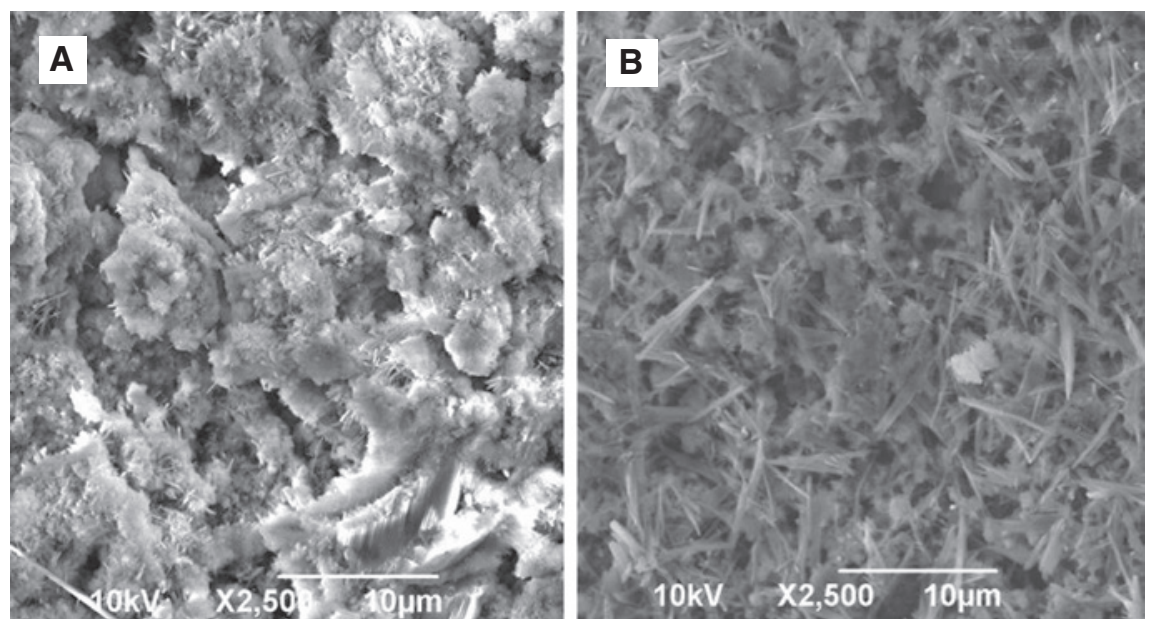

Figure 1: SEM pictures of PCCS without the addition (A) and with maximum amount of nanostructured $\gamma-\mathrm{Al}_{2} \mathrm{O}_{3}+2.5 \%$ RDP- 22 wet mixing (B). 
without additions. As for the specimen with $\gamma-\mathrm{Al}_{2} \mathrm{O}_{3}$ and RDP-22, the gel phase is almost absent. Meanwhile, it has to be pointed out that specimens with $\gamma-\mathrm{Al}_{2} \mathrm{O}_{3}$ and $\mathrm{RDP}-22$ have crystallites of equal size, which compose the cement stone.

\subsection{Small angle neutron scattering}

SANS allows characterising materials at the microlevels and nanolevels, providing statistical information, averaged over a macroscopic volume. Parameters such as diameter, concentration, volume fraction, and area of interface can be monitored by measuring the scattering of neutrons from the samples in angles smaller than $5^{\circ}$. SANS makes possible investigations on fine-pore porosity without any drying or pretreatment of specimens, as required by other techniques used to measure the porosity and the pore size distribution. In general, the low angle part of the SANS scattering curves $(q R<1)$ contains information about the overall sizes of the scattering objects; the medium angle region characterises the particle shape; and at larger scattering vectors, the characteristics of the interfaces can be deduced. $q$ is the scattering vector, defined by the neutrons' wavelength and the scattering angle, whereas $R$ is the size of the scattering particle. The scattering intensity curves are modelled by mathematical functions, involving parameters that reflect the structural features of nanoscale inhomogeneities in the studied sample. The theoretical base of the SANS technique can be found in various references $[2,17,18]$.

The structure of cement and concrete materials usually exhibits a fractal character; the fractal dimensions are correlated to the mechanical properties of the cements, especially to the mechanical strength of them, but they also reflect the interface quality, the degree of the porosity, and the openness of the structure. Following the change of the fractal dimension while adding different components (mineral and/or polymeric substances) to the base material, we can understand how the introduction of these additives influences the internal surface changes, what is connected to the mechanical properties of the material.

The studied samples were $10-20 \mathrm{~mm}$ in diameter and have a thickness of 0.1-10 mm.

The SANS measurements on the samples described in Section 2.1 were carried out using the Budapest Neutron Centre's SANS diffractometer, Yellow Submarine. The used sample to detector distance was the maximum available (5.6 m); the used wavelengths were 3.68 and $11.22 \AA$. Figure 2 shows the studied samples in the neutron beam.

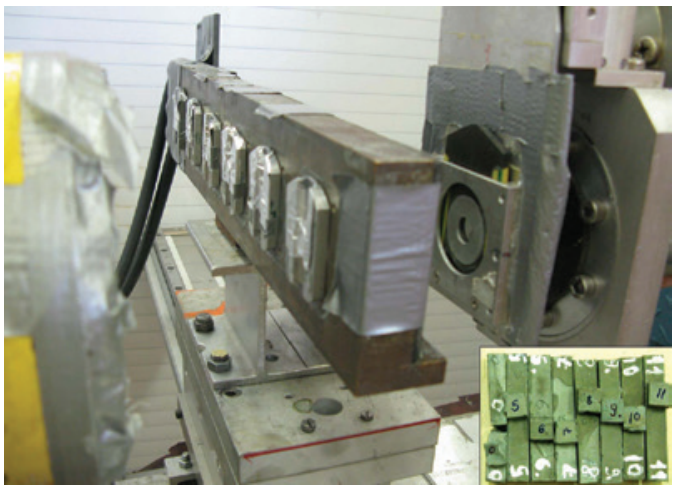

Figure 2: PCC samples in the neutron beam.

The numerical processing of the SANS data consisted of an instrumental calibration (BerSANS software, HMI, Berlin, Germany) followed by a circular averaging; the final data set was then treated by the Wavemetrics Igor Pro software (Portland, OR, USA) [19].

The intensity $I(q)$ was plotted versus the scattering vector $q$ on a logarithmic scale, and its interpretation relies on the fractal type behaviour of the system.

The used fitting model was a power-law function:

$$
I(q)=A^{*} q^{-p}+b k g
$$

where $A$ is a constant containing the sample and the instrument characteristic parameters, $p$ is the fractal exponent, and $b \mathrm{~kg}$ is the incoherent background noise. The intensity was represented as arbitrary.

\section{Results and discussion}

Cement-based systems with added RDPs were studied because it was assumed that these polymers change the structure of concrete when the binding agent and water form the cement stone, which joints the particles together to produce a monolith.

When removing water from concrete, the polymer forms a thin layer on the surface of pores and cement aggregate nodules; this layer has good adhesive behaviour.

The cement stone is a porous material composed of fractally arranged microscopic grains. The porosity of the system - related to the mechanical strength - is characterised by the fractal dimension. When porosity reaches its critical point, the strength will appear as a constant. The lower is the porosity, the higher is the compactness; therefore, a higher fractal dimension is a characteristic of a higher compressive strength [5]. 


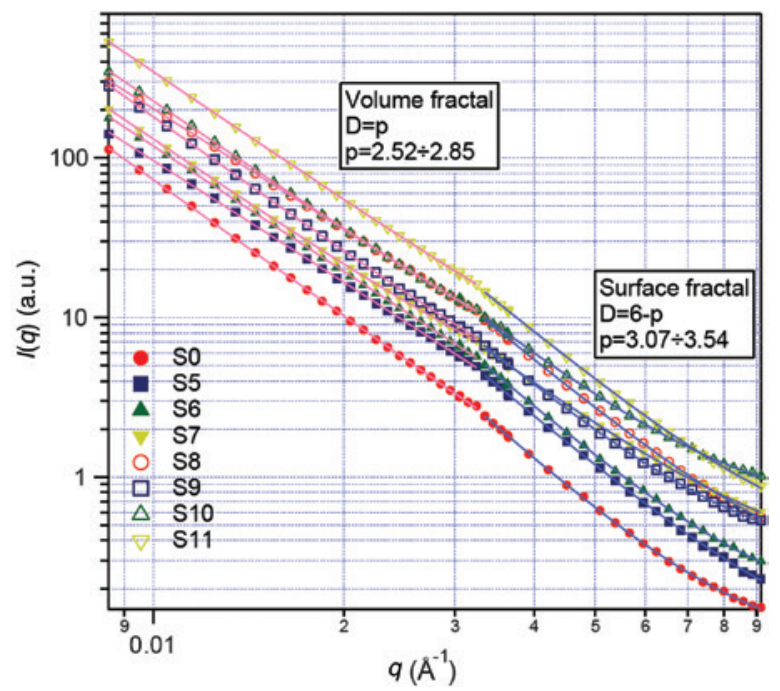

Figure 3: Averaged intensities from the SANS measurements represented versus the $q$ scattering vector.

The straight lines are the fitted model curves.

Eight cement samples were measured; each sample showed two different fractal regions (Figure 3). Both regions were fitted by Equation (1). The fitting parameter $p$ defined the $D$ fractal dimension as follows: if $2<p<3, D=p$; if $3<p<4, D=6-p$.

The fitted parameters are listed in Table 3.

The $q=3.25 \times 10^{-2} \AA^{-1}$ scattering vector value defined the crossover point between the two fractal regions. Below this $q$ value, the grain-pore structure represented volume fractality, whereas, above the crossover point, surface fractal behaviour occurred. The first one, volume fractal region, showed fitting exponents between 2.52 and 2.85, which corresponds to the $D$ fractal exponent, whereas the surface fractal region had fitting exponents between 3.07 and 3.54, which corresponds to fractal dimension between 2.92 and 2.46 (Table 3). The addition of the $\gamma-\mathrm{Al}_{2} \mathrm{O}_{3}$ and

Table 3: Fitted parameters ( $p 1$ and $p 2$ are exponents of the two different fractal regions; D1 and D2 are the corresponding fractal dimensions).

\begin{tabular}{lrrrr}
\hline Sample & p1 & D1 & p2 & D2 \\
\hline S0 & 2.85 & 2.85 & 3.54 & 2.46 \\
S5 & 2.52 & 2.52 & 3.35 & 2.65 \\
S6 & 2.61 & 2.61 & 3.43 & 2.57 \\
S7 & 2.70 & 2.70 & 2.87 & 3.13 \\
S8 & 2.51 & 2.51 & 3.30 & 2.70 \\
S9 & 2.84 & 2.84 & 3.29 & 2.71 \\
S10 & 2.71 & 2.71 & 3.07 & 2.93 \\
S11 & 2.69 & 2.69 & 3.26 & 2.74 \\
\hline
\end{tabular}

The fitting errors for $p 1$ and $p 2$ are \pm 0.005 and \pm 0.02 , respectively.
RDP to the cement control sample (S0) changed the inner structure of the sample.

So did not contain any additives, and its volume fractal dimension was the highest, whereas, in the surface fractal region, S0 showed the lowest fractal dimension. This behaviour is connected to the inner grain-pore structure: the surface fractality increased with the addition of the different components, whereas the volume fractality decreased. The increase of the surface fractal dimension towards 3 is explained by changes in the surface relief of the grains and pores, namely, a surface coagulation occurs with the covering of pores' inner surface by the additive film. The volume fractal region behaviour is also related to the effect of the additives on the cement structure: the fractal dimension decreased after the $\gamma-\mathrm{Al}_{2} \mathrm{O}_{3}$ and RDP were added. We can explain it by a compaction of the grain-pore system, which is related to higher mechanical strength. Smaller pores and higher surface roughness give higher structural stability to the system. The development of the fractal surface and fractal volume is also dependent on the used mixing procedure; however, its influence cannot be clearly distinguished from the influence of the additives.

The behaviour of S7 was different from all the other samples: this sample showed only one type of fractality, namely, volume fractal. This sample was prepared by the addition of polymer; however, without $\gamma-\mathrm{Al}_{2} \mathrm{O}_{3}$, dry mixing was applied. Therefore, we can conclude that, when dry mixing is applied, the addition of mineral is necessary to achieve the optimum structural changes in the cement, namely, to achieve the deposition of the polymer on the pores' inner surface that increases the mechanical strength of the material.

\section{Conclusion}

The SANS investigation of different PCC specimens made of Portland cement with added $\gamma-\mathrm{Al}_{2} \mathrm{O}_{3}$ and RDP has been performed. The objective of the measurement was to verify the assumption that these polymers change the concrete's structure when the binding agent and water form the cement stone that joints the particles together to make a monolith. The additives decrease the fractal dimension in the volume fractal region and increase the fractal dimension in the volume fractal region, meaning a higher structural stability of the system. The modification of cement creates preferably a smaller-sized structure of the cement stone.

The present work confirms the industrial applicability of SANS in completing the characterisation of cements (including dense cements and cement stones), 
demonstrating the complementarity of this technique with conventional methods. The obtained results can be used to optimise the cement production for distinct purposes and achieve a better final quality of the product.

Acknowledgments: Financial support from EU's NMI3 (Seventh Framework Programme) is acknowledged.

\section{References}

[1] Fursa TV, Surzhikov AP, Osipov KYu. Russ. J. Nondestr. Test. 2006, 43, 95-99.

[2] Rogante M. In Proc. 1st Italian Workshop for Industry "Industrial Applications of Neutron Techniques," Rogante Engineering: Civitanova Marche, Italy, 2008, p 40.

[3] Rogante M, Rosta L. In Proc. SPIE 5824, Opto-Ireland 2005: Nanotechnology and Nanophotonics, Blau WJ, Kennedy D, Colreavy J, Eds., SPIE: Bellingham, USA, 2005, p 294.

[4] Rogante M, Capelli G, Domanskaya IK. In Proc. 3rd Int. Conf. "Mechanical Technologies and Structural Materials" MTMS2013, Živković D, Ed., Croatian Society for Mechanical Technologies: Split, Croatia, 2013, p 69.

[5] Ficker T, Len A, Němec P. J. Phys. D Appl. Phys. 2007, 40, 4055-4059.

[6] Ficker T, Len A, Chmelík R, Lovicar L, Martišek D, Němec P. Europhys. Lett. 2007, 80, 16002.
[7] Allen AJ, Windsor CG, Rainey V, Pearson D, Double DD, Alford NMcN. J. Phys. D Appl. Phys. 1982, 15, 1817-1834.

[8] Pearson D, Allen A, Windsor CG, Alford NMcN, Double DD. J. Mater. Sci. 1983, 18, 430-438.

[9] Allen AJ, Thomas JJ, Jennings HM. Nat. Mater. 2007, 6, 311-316.

[10] Puterman M, Malorny W. In Proc. 9th Int. Congress on Polymers in Concrete-ICPIC 1998, Bologna, Italy, 1998, p 165.

[11] Domanskaya I, Kapustin F, Mokhort E, Oleynik V. In Proc. 15th Int. Conf. on Building Materials "Ibausil," Weimar, Germany, 2003, Vol. 2, p 523.

[12] Dimmig A. In Proc. 11th Int. Congress on Polymer in Concrete IX.ICPIC, BAM: Berlin, 2004, p 19.

[13] Wang R, Wang PM, Li XG. Cem. Concr. Res. 2005, 35, 900-906.

[14] Bhikshma V, Rao KJ, Balaji B. Asian J. Civil Eng. (Build. Housing) 2010, 11, 563-573.

[15] Kruglitsky NN, Boyko GP. Physico-Chemical Mechanics of Cement Polymer Compositions, Naukova Dumka: Kiev, 1981.

[16] Vasiliev V, Bazhenov A, Vladimirova E, Kozhevnikov V, Nosov A, Mohort E, Chistyakova T. Patent RU 2384522 C1: Method of Obtaining Oxide Nanoparticles of Metal, Institute of Solid State Chemistry of the Ural Branch of the Russian Academy of Sciences, 2010.

[17] Rogante M. Caratterizzazione, mediante scattering neutronico, di materiali e componenti per l'impiantistica nucleare ed industriale, Ph.D. thesis, University of Bologna: Italy, 1999.

[18] Williams C, May RP, Guinier A. In Characterisation of Materials, "Materials Science and Technology," VCH Verlagsgesellschaft: E. Lifshin Ed., Weinheim, 1994, Vol. 2B, p 611.

[19] Kline SR. J. Appl. Crystallogr. 2006, 39, 895-900. 